\title{
'Do you really want me to tell ya!' critical learning in engaging young people in contact with the justice system as peer educators with social work students
}

\section{Johanna O'Shea \& Emma McGinnis}

To cite this article: Johanna O'Shea \& Emma McGinnis (2019): 'Do you really want me to tell ya!' critical learning in engaging young people in contact with the justice system as peer educators with social work students, Social Work Education, DOI: 10.1080/02615479.2019.1663813

To link to this article: https://doi.org/10.1080/02615479.2019.1663813

View supplementary material $๘$

曲 Published online: 08 Sep 2019.

Submit your article to this journal $\widetilde{ }$

Џ Article views: 64

Q View related articles $₫$

View Crossmark data $־$ 


\title{
'Do you really want me to tell ya!' critical learning in engaging young people in contact with the justice system as peer educators with social work students
}

\author{
Johanna O'Shea (iD) and Emma McGinnis ${ }^{\mathrm{b}}$

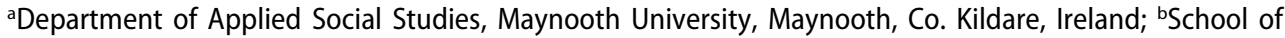 \\ Applied Social and Policy Sciences, Ulster University, Derry, Northern Ireland, United Kingdom
}

\begin{abstract}
This paper outlines and evaluates an active and experiential learning project, which gave young people involved with the justice system, a voice as peer educators engaging with social work students outside of the traditional educational institution. The project had two key interconnecting elements. Firstly, by engaging a hidden population of young people in a realistic and meaningful way, it enabled them to share their experiences, and allowed students to understand the complexity of what it means to be socially excluded. Secondly, through this active participation process the young people began to see education as a desirable goal.

The project took place over three months and included 10 social work students and 13 young people involved with the justice system. Creative use of multimedia facilitated production of a learning resource to capture the young people's lived experiences with statutory social work and justice systems. Young people were fundamentally challenged in their beliefs about themselves being involved in education to achieve a qualification. Students were challenged in their creativity and versatility responding to the task, when collaborating with 'hard to reach' young people. They were furthermore challenged in terms of their attitudes and assumptions in relation to offending and social justice.
\end{abstract}

\section{ARTICLE HISTORY}

Received 18 March 2019

Accepted 16 August 2019

\section{KEYWORDS}

Users perspectives; user participation; social justice; criminal justice social work; youth justice; narrative approaches; person centered; students; higher education

Approaches to social work education about young people tend to reflect the practice experience where dominant knowledge discourses inform policy and practice frameworks. The risk paradigm (Kemshall, 2010) is such an example; Stanford (2011) notes the impact of risk technologies associated with the growing risk agenda in practice, for example as evidenced in methods of practice regulation including actuarial assessment approaches as means of risk calculation. Such rationalizations according to Parton (1998) and Ferguson (2007) can be complicit in reducing the complex lives of service users to homogeneous categories of need and risk. Implications for social work undergraduate learning environments can mean dominant paradigmatic approaches to identifying and assessing needs and risks, occupy significant space in curriculums. Regulatory and professional bodies such as Social Work England (see Conway, 2019), 
and Northern Ireland Social Care Council (2015), assert a commitment to user involvement in social work education. However programmes striving to meet the range of stakeholder requirements can find themselves stymied in integrating meaningful user involvement which Driessens, McLaughlin, and van Doorn (2016) caution requires time, funding, flexibility, and institutional support. Meaningful user participation premised on social justice values, should authenticate experiences and expose institutionally oppressive practices (O’Brien, 2011). Excluded young people will often have lengthy experience with social work services, yet as Freake, Barley, and Kent (2007) and Pinkney (2011) attest, little is understood of how they experience professionals within these, and their views on how they should be treated and better supported.

Justice involved young people are over-represented in prevalence on mental health, communication, and education and learning needs. A causal link between enduring childhood poverty, trauma, adverse experiences, and justice system involvement, is established (McAra \& McVie, 2010). Of those in custody, 90\% have been educationally excluded, 95\% experience at least one mental disorder, and almost one third have a general learning disability (Campbell \& Abbott, 2013). The Taylor Review of Youth Justice (Taylor, 2016) highlights the centrality of education to reducing youth offending and inequalities.

Because of the intersectionality of experiences across multiple services, young people have a depth of systems knowledge and experience, yet theirs is often the hardest story to access, and perhaps harder to tell. The terms 'hidden' and 'hard to reach' whilst contested, are applied to groups who because of their experience of multiple inequalities become or feel forced to be hidden (Flanagan \& Hancock, 2010). Appreciating both the physical and psychological barriers of engagement is paramount to accessing their narrative. This involves listening to service users and people who know them best. Transparency, compassion, care and humanness; meaning the importance of spending time, are essential to achieving participation with young people who offend and may or may not want to be hidden (Creaney, 2014). For engagement to be meaningful it must have value and purpose for the person, as opposed to reinforcing otherness.

The Young People as Educators project aimed to bring together social work undergraduate students and young people involved with the justice system to develop a multimedia product about the young people's experience of social workers, and perspective on what they need from them to genuinely support and help them. Through a 'process of creative critical dialogue' (Cowden \& Singh, 2007, p. 5), it was anticipated that students would develop a genuine understanding of the needs and circumstances of young people. Furthermore, young people as 'educators' contribute their knowledge expertise to jointly develop a DVD learning resource available to social work programmes. Additionally, all participants receive an Open College Network $(\mathrm{OCN})$ media technology award in recognizing skills developed in producing the resource. Vocational accreditation was a key objective in evidencing meaning in an educationally focused project.

The approach is radical, 'turning on its head' both young people's, and others assumptive views of themselves and their capabilities; young people engaging with students, lecturers and media designers in co-producing the teaching resource. This knowledge exchange is critical in co-production that aims to engage service users as citizens in a consensual exchange, not 'picked out' as 'experts' for a one-off engagement. 
Such methods, although satisfying what Barber (2009) understands as the consumerist needs of institutions and providers, often further preserves the silos of 'them and us'. Alternatively, through engagement over time with degree level students, it was hoped that young people might reframe their assumptions about themselves in education, hopefully envisioning it as creative, accessible and possibly achievable, factors highlighted by (Driessens et al. (2016), in a similar project with homeless young people. Involvement with the project could potentially empower participants as active citizens contributing their views and experience to assist future professionals in training.

Methodology

This active (Skinner, 2010) and experiential learning (Kolb, 1984) project used a qualitative approach as the optimum method in addressing the aim of enabling young people who are typically excluded in discourses on service user experiences, to tell their story. This was premised on a social justice approach which holds that 'hidden' or 'hard to reach' groups are structurally excluded through processes that 'stigmatise' and 'other', such as justice, educational and care systems (Ellard-Gray, Jeffrey, Choubak, \& Crann, 2015). Proactively finding opportunities that are safe, positive and potentially enriching is therefore fundamental. Focus groups were initially used as they offer 'expert by experience' group participation, encouraging collective ownership and control of the discussion topic (Seale, Gobo, Gubrium, \& Silverman, 2004). For 'hidden populations' this can be important in offsetting conventional power-laden practices that purport to seek their views; in this case the one-to-one young person/social worker encounter. Focus groups encourage a creativity and responsivity from group members, what Stewart, Shamdasani, and Rook (2015) see as the production of rich understandings where young people co-construct their story about their experience, in their time. Broad themes emerging from the focus groups informed the schedule for interviews ${ }^{1}$. Kitzinger and Barbour (1999) advocate a combination of both qualitative methods in capturing the range and subtleties of perspective in a group, along with the opportunity for individual sharing of experience that may not be forthcoming in the collective environment. As example, in interview young people opened up about some deeply personal and sensitive experiences which otherwise may not have been captured. This qualitative project developed organically at a pace, and in spaces that met the needs of the young people. This provoked students to rethink assumptions about how and where meaningful relationship building should occur.

Ethical approval for this project was granted by Ulster University at school level. Furthermore, approval and access were granted by the Youth Justice Agency (YJA) and the Northern Ireland Prison Service (NIPS).

\section{Sampling and recruitment}

This was a cross agency initiative between Ulster University, Hydebank Wood College, the YJA and the Bytes community project ${ }^{2}$. The rational for including the Bytes project was to establish a link with an accessible local skills-based organization that the young people might potentially continue to engage with following completion of the project. This project had two strands running simultaneously over a three-month period in 2016. For inclusion in the project students needed to have successfully completed one placement in order to have had a level of hands-on experience in the social work role, 
albeit as a student. Following a project information event open to the second year group, 10 students self-selected; five into each project strand.

Purposive sampling was used to recruit young people through the YJA, and the Bytes project for the community strand of the project, and through Hydebank Wood for the custodial strand. The inclusion criteria required that young people were involved with the justice system, usually reside in the Greater Derry area and that participation was entirely voluntary. Young people in the community project were offered the incentive of time spent on the project contributing toward hours off community sentences. Seven young people living in the community between 17-19 years old were recruited, with two dropping out early in the project. Of the remaining five, one was female and the rest male, with all students in the community project being female. The project in custody involved eight young male adults (aged 18-23), engaging with five students; one male and four females.

\section{Data collection and analysis}

A comprehensive evaluation was undertaken at various stages and increasingly in the concluding phase of the project. Pre- and post-questionnaires were completed by the students primarily in relation to their knowledge of and attitudes to young people involved in the justice system ${ }^{3}$. Given the experiential learning nature of the project, many informal opportunities existed to talk with the young people about their experiences, which were important for the students to reflect upon during weekly planning sessions. To ensure the engagement remained balanced in terms of sharing personal information, young people initially interviewed the students about their biographies and experiences studying at university. Data collection was an iterative process, each stage informing subsequent stages and all material was recorded. The timing and organization of the focus groups and interviews was important to the process. As one student commented:

'Spending a few weeks getting to know them prior to discussing personal experiences allowed for the interviews to be more open and relaxed,...' (Student Hydebank (SH)).

Having worked in establishing a level of trust and rapport one focus group took place at the prison and two in the community, both were facilitated by the project leads with experience in focus group facilitation and co-facilitated by the students. Semi structured interviews were conducted by the students with the young people. The custodial element occurred over nine full days which were flexibly structured around games and sporting activities along with informal 'downtime' between the students and young people. Sharing lunch together proved to be an important part of the daily routine. By contrast, engagement with the young people in the community strand was often opportunity led, ad hoc and unpredictable. Contact time for scheduled focus groups and interviews always occurred in a safe neutral environment agreed on with the young people. Providing transport to and from sessions, scheduling these in the afternoon, and providing food were all basic to the young people's participation in the community. This strand included a young pregnant woman who preferred additional individual sessions to share her experiences and perspectives. Subsequent work on the award contributing to the production and editing of the DVD took place in the Bytes facility in the city center. In total students worked over seven cumulative days contact 
in the community with the young people. The learning spaces that the project occurred in all usurped the traditional classroom environment, for example outdoor/gym-based activities, an adventure learning center, pool clubs, and the Bytes project. However, none more unconventional than the chapel in Hydebank Wood, which owing to a range of complex logistical factors became the only available space and therefore the hub for project activity in the custodial setting.

Focus groups and interviews were analyzed using thematic analysis to identify emerging themes and patterns (Braun \& Clarke, 2006). Students were encouraged to keep reflective logs throughout which were used in the process evaluation of the project. The rating and likert scale questions on the students' evaluation forms invariably showed an improvement in knowledge, understanding and attitudes. Given the small sample sizes, this data was not analyzed quantitatively; rather it was used to inform further discussion and exploration of the issues. Audio, video recordings, and photographs of young peoples' and students' engagement produced by both project strands were combined and edited to create a composite DVD learning resource about their experiences, and how social work could better support them.

\section{Active and experiential learning process}

This project was inclusive and flexible in its approach, adapting during the implementation phase in meeting the needs of the learners (students) and educators (young people). For example, having listened to the views of the young people, the learning environment for the community-based strand partially changed to activity-based adventure learning in an outdoor activity center. Similarly the venue for the custodial strand changed from the university campus to Hydebank Wood to ensure young people on remand and ineligible for temporary release, could also participate in the project.

Along with group planning sessions, adventure learning and focus groups, young people in the community strand gradually felt sufficiently confident to 'drop in' to the Bytes project, wanting to move on with their award supported by center workers. Students responded by being flexible in arranging individual interviews suitable to the young people. Interestingly, both valued the opportunity to attend the center at the same time, helping each other with the award, editing the DVD and enjoying a laugh. Nobody underestimated just how much this must have taken for some of the young people in terms of their complex needs.

Students were very proactive in planning activities on an ad hoc basis in the challenging custodial environment, where security requirements often changed suddenly and unexpectedly, restricting movement and access to facilities at short notice. The rules of engagement, particularly in relation to the use of multimedia equipment as well as specific activities for project days had been agreed in advance of the project with prison management, however new challenges arose on almost all project days renegotiating security access with multimedia equipment to and from the prison; reestablishing agreed rules around the use of the equipment within the prison grounds; ensuring the young people were kept informed of agreed project dates and were permitted to attend; as well as gaining access to sports facilities to follow through on planned activities. It was in this context in the initial project phase that a break from the prison regime was negotiated at the students' request allowing all project participants to 
stay together for the full project day including sharing a meal at lunchtime. This required careful negotiation as all young people would usually return to prison wings for their lunch and then to be locked up during the prison staff lunch break.

Another example occurred one morning when news filtered through informing of the tragic death of a prison officer due to injuries sustained in a dissident car bomb attack days earlier. Students were challenged to cope in the highly charged atmosphere amongst prison staff that day, balancing the need to be respectful to colleagues of the officer, whilst fulfilling their commitments to the young people. Skilled negotiation and patience allowed students and young people to engage together for two hours that afternoon, clearly reinforcing to the young people the student's reliability and commitment to them.

The student engagement with the young people was an integral part of both strands of the project experience providing meaningful learning for them in debunking many of the myths about building genuine relationship with 'hard to reach' young people. For example, an important principle from the outset was that no young person would be excluded from the project for reasons related to their offending behavior. This proved to be particularly challenging when a female student became aware that one young person from her hometown had a conviction for rape. It was testament to the student's resolve to try to overcome her anxieties and continue to engage with this young man. As the weeks passed they worked well together and on the final project day spontaneously hugged each-other as the students left the prison for the last time.

To mark the end of the project and celebrate everyone's achievement two separate dinner and award ceremonies were held, one each in the community and custody setting, both were attended by academic colleagues, referring agency staff and key workers. Young people and students received their OCN award and Certificate of Participation from Ulster University. As an appreciation of their efforts the young people received a gift of a sports voucher or money paid to their prison 'tuck-shop' accounts and a comic book the students had created with visual materials from the project.

\section{Key findings}

Key messages from the young people in relation to what they needed from social work centered around two main overarching themes; firstly, feeling valued and respected as a person; and secondly feeling empowered in critical life changing situations.

\section{Theme 1 feeling valued and respected as a person}

Young people repeatedly expressed the need to feel valued as a person, the need to be treated with respect, to be cared about and to have their wishes and feelings taken into consideration. Their personal stories suggested that even at a relatively young age they were able to tell very quickly if a social worker was in fact interested in them as a person. The relational aspect of encounters was valued and always brought to the fore as opposed to the procedural and professional nature of meetings with social workers. Spending time with the young person to get to know them and allowing time and space to understand their situations and perspectives was interpreted as a key 
indicator of the social worker taking a personal interest in them. One young person recalled experiences when he was aged 7 or $8 \ldots$

'One social worker took me out places. Yeah he was interested in me, wanted to get to know me. The other one did nothing ... none of that'(Young Person Hydebank (YPH)).

Another young person's comments highlight how nuanced and skilled he had become in ascertaining almost instantly if a social worker cared about him ...

"You just want them to take time, you know straight away if they care, if they can be bothered" (Young Person Community (YPC))

One young person recalled his negative experience in the Family Proceedings Court

'Instead of reading the report ... come and actually ask the questions, ask me what I think'(YPH)

with another young person recalling how critical it was for him being able to share his views ...

'We'd sit before the case conference and go over everything and $X$ (name) would listen to what I thought, what I wanted...' (YPH).

Again, the critical issue of having time and space for the young person helping them to make sense of what was occurring could not be over-stated ...

'He always explained what was happening .... I had a youth justice worker $Y$ (name) and we had a good talk every week, just going over everything, how I was getting on you know.' (YPC).

When asked about what makes a difference in a social worker, honesty, openness and listening were key qualities held in high regard "they treat you as a person; they listen to you; they care ... . (YPC). It was further observed that young people used the social worker's real name when recalling positive experiences, whereas simply 'social worker' when recalling negative experiences, possibly dehumanizing the memory of some professionals involved in their lives.

"X-(name) explained everything ... let me know what was happening ... the others did none of that." (YPC)

The alacrity with which young people believed they could determine whether a social worker was authentic and genuinely wanted to help them was alarming to students. This brought home to them the 'revolving door' nature of multiple systems and social workers impacting in their lives and their needing to almost develop an early warning filter to cope and survive this.

\section{Theme $\mathbf{2}$ feeling empowered in critical life changing situations}

Young people described detailed experiences, which were perceived as major crises and life changing for them. For example, family court hearings where care and safeguarding issues were being considered, or youth court attendance when being sentenced, were particularly distressing. The role of the social worker was critical here in providing accurate information in an age appropriate manner; advising on their rights and advocating on their behalf where necessary. Young people appreciated situations where the social worker explained processes and decisions. One young person described his experience in court at age 12 and how in such situations,

'a good social worker tells you straight, what is happening, what you need to know.' (YPC) 
The young people identified being empowering as critical to the social work role. They recalled experiences where they clearly needed somebody to advise on exactly what they could do to influence the situation and take some control over their own lives.

'He told me what my rights were, not just what was happening...' (YPH)

'I knew what I had to do to change my situation. I knew because he helped me go the right way about it...' (YPH)

as opposed to perceived threats ...

'the others said if you don't go to the Children's Home, we'll go to court and you'll not be able to go back home until you are 18. I went voluntarily then' (YPH).

During periods in state care or juvenile justice centers, young people recalled experiences of feeling isolated and disempowered; social workers advocating on their behalf during such times was significantly valued. One young person highlighted how his social worker advocated on his behalf at his Looked After Children's statutory review meetings to re-establish contact with his sibling ...

'only for him, I might not have seen my wee brother again, yeah $X$ (name) always stood up for me' (YPC)

Young people also shared how accessing knowledge about, and practical support with basic life tasks could be life changing. One young person who had spent time in children's homes and youth custody spoke of how support from his youth justice worker with completing forms for college, including contacting the benefits agency on his behalf and liaising with college staff meant attending college was a real prospect for him. The young person understood the trusting relationship he had developed with his key worker to be an indication of investment in him and as a result he felt motivated to prove himself. 'Where' help occurred meaning the physical space this happened in mattered greatly. Two young people shared how they had found probation service interview rooms to be intimidating environments ... 'The first time I was at probation,... . I was a bit nervous. It was not a nice environment ... I was like down in a wee cell in a tiny box room, it looks like an interview room in a police station' (YPC). This issue of the location or 'place' of the support, proactively going to young people and giving them choice in deciding on where is safe for them mattered hugely.

\section{Key messages from the young people on their project participation}

Feeling valued and being empowering were key themes reflected by the young people about their participation in this project. Their expert status and knowledge was the underpinning ethos of this project, with students and tutors as learners in the situation. Seeing social work students' efforts practically in reaching out to them, and being curious about their experiences of social workers in the past, was greatly appreciated. Consequently, young people believed that these students might practice differently when qualified, as evidenced by one young person when he said ...

'Youse have seen what it was like for us ... so you'll learn how to do it better' (YPH)

Another young person felt that the resource created (the DVD) would help others to avoid the mistakes he had made...

"I want to help other young people. I've seen what it is like to be in prison and it's not nice. I want to help others not make these mistakes" (YPH). 
One young man's response when asked what he thought of the project captured this principle perfectly ...

... 'It was nice to be the teacher for a change' (YPH).

Taking ownership of the project alongside social work students was important to the young people. It was originally assumed and planned that all participants' names would be anonymized, and all project materials edited to ensure that no individual could be identified. However, as the project progressed, the young people increasingly objected to this preordained idea and insisted that they should be identifiable in 'their' project. Some comments to illustrate their feelings were:

'Nobody hid my name when I was sentenced in court'

'Everybody in Derry knows I'm in prison. Why can't they know now that I did something good here'

'... (laughs) ...... My face was splashed across the Sunday Life, don't worry about it coming out that I'm in prison'

Considerable debate occurred with all participants both in a group setting and individually concerning the possible consequences of identification. Future hypothetical situations where this may be an issue, for example employment, were debated at length. Ultimately the young people were adamant that they did not want to be hidden, and ironically the project team received one of many humbling lessons about paternalistic preconceptions and assuming to know what they needed. Written consent was obtained, and this process was agreed with the NIPS through the governor's office and with the YJA. The format of the DVD was subsequently changed in allowing the young people to be identified by their images and first names, which allowed them to take more ownership and pride in the success of the project they were creating.

The fun aspect of the project was also critical for the young people, who acknowledged that they were initially very apprehensive about engaging with social workers, ....

'but it's been completely different... It's been good craic like. It's definitely been enjoyable' (YPH)

\section{Key learning for social work students from their project participation}

Students kept ongoing reflective logs which were shared with tutors and used to reflect on learning experiences and to consider changes to improve ongoing project plans. For example, the students in the custodial strand identified a key highlight of each day as the experience of sharing a meal together with the young people, which seemed to contribute to all project participants feeling of equal value and developing positive relationships with one another. One student remarked 'We sometimes heard far more about what it was like living there while chatting over lunch or playing football than we did in the sessions.' (SH)

In depth evaluation of the reflective logs indicated some further key learning points. Importantly, students spoke about how the experience helped them to review their prejudicial and discriminatory attitudes toward these young people. Having the chance to build those relationships enabled students to appreciate the young people's experiences and challenge their own and others stereotypical assumptions about them. One student wrote; 
'I feel embarrassed about how my attitude was towards young people in the justice system ... as many students as possible should do something like this, I see young people in a totally different way' (Student Community (SC))

with another student noting ...

'My attitude to young people has totally changed' (SH).

One student discussed how she had essentially dehumanized these young people viewing them more as 'offenders' rather than young people. She remarked how surprised she was that ... 'they're just young people who need a bit of help and support' (SC)

Students were initially quite surprised and relieved at how quickly the young people engaged with them as university students. A key learning point was that fundamental values of listening; being non-judgmental and respectful go a long way. In the custodial strand prison management staff observed on several occasions how remarkably well the students and the young people engaged and were at ease with one another. It seems that efforts to reduce the power imbalance between the students and the young people was key to establishing such positive relationships in a short time.

'The ability to place control in the young people's hands allowed us to develop a good relationship with the boys. The fact that they interviewed us too was just brilliant' (SH).

"Having "hard to reach" service users as partners in the project is in my opinion vital to the success of it ... It also addresses the power imbalance of "them and us" ' (SH)

These students clearly had a much deeper understanding of the reality and sometimes harshness of the prison experience for young people.

'All social work students should get the chance to do something like this, until now I thought people who went to prison deserved to be there. ... I don't now' (SH).

Students in the community strand of the project furthermore identified the importance of realizing how chaotic, and unpredictable the reality of day to day life for the young people could be. They demonstrated a much deeper appreciation of the need for humor, flexibility, creativity and responsiveness in working with young people in such challenging circumstances.

\section{Discussion}

This learning project aimed to not just ascertain the views of young people who are hidden from the mainstream, but by employing a social justice ethos and framework, was premised on the view that as human beings young people want to achieve, have a sense of worth, contribute, be valued for their contributions, and realize their human and social potential (Barry, 2010; MacDonald, 2015). The cumulative impact of exclusion and multiple inequalities experienced over time creates otherness, young people become concealed or hidden by layers of oppressive practices, environments and systems that further problematise them. Custody arguably represents the bluntest form of concealment. The literature supports the position that social gains and young people transforming their 'scripts' are essential to desisting from offending (Muncie, 2015). In this project it was essential that time, effort and expertise were acknowledged, providing a tangible achievement through the OCN award aimed to recognize participants' achievement whilst also instilling possibilities, links to further learning and selfefficacy in the task. 
Feeling valued and respected emerged as a key theme, in practice this meant being treated with thought, care and being listened to. Again, whilst evidence supports this (Hill, 2006; Martin, Romas, Medford, Leffert, \& Hatcher, 2006; Stein, 2015), the strength of feeling, genuineness and intent with which the young people expressed and reiterated this point was powerful and arresting to observe. The learning here for students could not be more profound; disadvantaged young people facing multiple inequalities and vulnerabilities, when actively facilitated to participate, upend the pervasive narrative of them as uncaring and a risk. A social justice approach to their needs and circumstances enables their agency in contributing and participating as citizens. Social justice and empowerment approaches espouse 'person in environment' however few service user participation endeavors enable this. As evidenced through this project, the task of taking the classroom to the person in environment is as complex and uncomfortable, as it is humbling and motivating. Yet as the project progressed, we observed numerous examples, not least in the secure custodial environment, where the more challenging and restrictive or even obstructive the circumstances on a given day were, the more determined and skilled the students became in negotiating these highly complex situations. Such was the commitment and sense of ownership students developed when given the responsibility and opportunity to engage actively in their own learning and demonstrate their commitment to the young people.

The second key theme identified young peoples' need for support that was practical, empowering in providing knowledge, and met their own articulated needs, not a prescribed version of these. Students learnt that young people do not adhere to the caricature/rhetoric; hearing them describe the trauma and losses they endured and the consequences of these and being at a loss to know how to deal with it, has no classroom equivalent. Often social work may have been instrumental in their concealment; professionals who neglect social justice values or disregard the individual lived reality, potentially collude in maintaining the offender-victim binary that seeks to disaggregate the relationship of needs and deeds, as highlighted by McAra and McVie (2010) and Pitts (2013) with notions of the deserving and undeserving recipients of welfare and social work services (Alcock \& May, 2014) being re-established in modern social work practice. Bringing the 'concealed' into the classroom or creating learning environments in spaces other than the sanitized safe zone of the lecture theater should be uncomfortable, unresolved and testing. However, the messages from the young people were disarmingly simple, making them even more provoking in that they reflect basic needs, identified and responded to with thought and care.

Limitations: This was a small-scale project involving 13 young people and 10 social work students across two separate project strands over a three-month period. The findings should therefore be considered in this context and whilst they challenge and expand our understanding of using creative means to hear the voices of 'hard to reach' populations, they are not generalizable, given the small-scale nature of the project.

The intention was to facilitate ongoing contact between the students and the young people through the Bytes community project; however, this occurred only on a handful of occasions and with the benefit of hindsight was perhaps too optimistic without structured and planned resources being available to facilitate this contact. It quickly became apparent to the students how difficult it was for the young people to maintain such a commitment given the often chaotic nature of their daily lives. Contact fizzled out not long after the 
project had formally ended as the students' exam period began and they began a long Summer break. Maintaining longer term contact with the young people whilst in the community and during further periods in prison ultimately was not feasible.

Two main factors were identified as barriers to further meaningful and creative engagement of 'hard to reach' populations in social work educational curriculums: 1 . a lack of substantial ring-fenced funding identified specifically for the purpose of active and experiential learning initiatives to engage hard to reach populations and 2 . the time needed to navigate complex and at times dysfunctional institutional systems within and between institutions; with the resultant ongoing uncertainty when actioning projects.

The students involved in this project continued their studies for a further year at the university and they presented the DVD from the project the following year to their peers. Their evaluation of the project experience remained very positive with several students still expressing a keen interest to work in this area after qualifying. Again limited resources and time constraints did not allow for a follow up with the students post qualifying. A long-term evaluation of the impact of the project experience for all project participants, which might have provided more insight into attitudinal and practical changes was therefore not possible.

\section{Conclusion}

Ulster University students were involved in the design and delivery of this project from the outset. It provided transformative, high quality, learning experiences through the promotion of meaningful staff student partnerships that engender a shared responsibility. It furthermore provided rich opportunities (Dill, Montgomery, Davidson, \& Duffy, 2016) for active and experiential learning in a supportive environment, in which innovative approaches to learning were encouraged, recognized, valued and rewarded. Students thrived when presented with the opportunity of meaningful engagement with 'hard to reach' young people in a relaxed and fun atmosphere.

This project demonstrates that social justice principles should underpin service user participation in social work education, translating as meaningful engagement over time, where power structures within the hierarchy of relationships are diminished as far as possible. Such an ethos promotes the dismantling of stereotypical assumptions and prejudicial views that students can bring to the educational setting and are potentially reinforced by curriculum decision making that includes certain service users, thus contributing to the concealment of hidden populations.

The YJA, the NIPS, university colleagues and particularly social work students, all expressed interest in such initiatives being repeated and consolidated within the social work curriculum. Yet we know that undertaking a project of this nature is hugely time intensive, additional to existing workloads, administratively complex, and not readily accommodated within institutional structures (Duffy, McKeever, McLaughlin, \& Sadd, 2017; Hatton,, 2017). In the current climate substantial ring-fenced funding specifically for the purpose of active and experiential learning initiatives to engage hard to reach populations, is required to realize purposeful and relationship based user involvement. Furthermore, this experience has taught us that facilitating meaningful user engagement is only possible with inter-institutional co-operation and a commitment to innovation and reduced bureaucracy. Educational institutions and all stakeholders, should consider 
more flexible agreements that provide greater autonomy within the curriculum. As social work educators we need to review curriculum design and delivery for the future workforce if we are to model those social justice principles we espouse as a profession, in our teaching practice and learning environments.

\section{Notes}

1. see appendix 1.

2. The Youth Justice Agency (YJA) works with young people involved with justice system under the age of 18, Hydebank College is the custodial facility for young adults 18-21 years old. Bytes is a community-based organization which uses internet and multimedia technologies to engage socially excluded young people, most of its users are 'NEET' (not in education, employment or training).

3. See appendix 2-5.

\section{Data Availability Statement}

The audio, visual and transcript data that support the findings of this study are available on request from the corresponding author, [JOS]. The data are not publicly available due to restrictions e.g. their containing information that could compromise the privacy of research participants.

\section{Disclosure statement}

No potential conflict of interest was reported by the authors.

\section{Funding}

This work was supported by the Department of Justice via Youth Justice Agency, Early Intervention Transformation Programme [Partial Funding of £6000].

\section{Notes on contributors}

Johanna O'Shea is a lecturer in Social Work at Maynooth University. She has a practice backgound in probation work in both Germany and Northern Ireland.

Emma McGinnis is a lecturer in Social Work at Ulster University. She has a practice background with many years experience in Youth Justice.

\section{ORCID}

Johanna O’Shea (D) http://orcid.org/0000-0003-3278-2660

\section{References}

Alcock, P., \& May, M. (2014). Social policy in Britain. London: Palgrave.

Barber, T. (2009). Participation, citizenship, and well-being: Engaging with young people, making a difference. YOUNG, 17(1), 25-40. 
Barry, M. (2010). Promoting desistance among young people. In W. Taylor, R. Earle, \& R. Hester (Eds.), Youth justice handbook: Theory, policy and practice (pp. 158-167). New York, NY: Routledge.

Braun, V., \& Clarke, V. (2006). Using thematic analysis in psychology. Qualitative Research in Psychology, 3(2), 77-101.

Campbell, S., \& Abbott, S. (2013). Same Old ... The experiences of young offenders with mental health needs. Young Minds. Retrieved from https://www.bl.uk/collection-items/same-old-the -experiences-of-young-offenders-with-mental-health-needs

Conway, C. (2019). Reshaping standards, enabling change. Social Work England. March 1st. Retrieved from https://socialworkengland.org.uk/

Cowden, S., \& Singh, G. (2007). The 'User': Friend, foe or fetish? A critical exploration of user involvement in health and social care. Critical Social Policy, 27(1), 5-23.

Creaney, S. (2014). The benefits of participation for young offenders. Safer Communities, 13(3), $126-132$.

Dill, K., Montgomery, L., Davidson, G., \& Duffy, J. (2016). 'Service user involvement in social work education: The road less travelled'. Retrieved from http://fieldeducator.simmons.edu/ Field Educator, 6 (2).

Driessens, K., McLaughlin, H., \& van Doorn, L. (2016). The meaningful involvement of service users in social work education: Examples from Belgium and The Netherlands. Social Work Education, 35(7), 739-751.

Duffy, J., McKeever, B., McLaughlin, H., \& Sadd, J. (2017). Service user and carer involvement in social work education-Where are we now? - Part 2. Social Work Education, 36(2), $125-127$.

Ellard-Gray, A., Jeffrey, N. K., Choubak, M., \& Crann, S. E. (2015, December). Finding the hidden participant: solutions for recruiting hidden, hard-to-reach, and vulnerable populations. International Journal of Qualitative Methods, 4(5), 1-10.

Ferguson, I. (2007). Reclaiming social work: Challenging neo-liberalism and promoting social justice. London: Sage.

Flanagan, S. M., \& Hancock, B. (2010). 'Reaching the hard to reach'-lessons learned from the VCS (voluntary and community Sector). A qualitative study. BMC Health Services Research, $10,92$.

Freake, H., Barley, V., \& Kent, G. (2007). Adolescents' views of helping professionals: A review of the literature. Journal of Adolescence, 30(4), 639-653.

Hatton, K. (2017). A critical examination of the knowledge contribution service user and carer involvement brings to social work education. Social Work Education, 36:2, 154-171.

Hill, M. (2006). Children's voices on ways of having a voice: Children's and young people's perspectives on methods used in research and consultation. Childhood, 13(1), 69-89.

Kemshall, H. (2010). Risk rationalities in contemporary social work policy and practice. British Journal of Social Work, 40(4), 1247-1262.

Kitzinger, J., \& Barbour, R. (Eds.). (1999). Developing focus group research: Politics, theory and practice. London: Sage.

Kolb, D. (1984). Experiential learning: Experience as the source of learning and development. New Jersey: Prentice Hall.

MacDonald, R. (2015). Youth transitions, criminal careers and social exclusion. In B. Goldson \& J. Muncie (Eds.), Youth crime and justice (pp. 209-223). London: Sage.

Martin, J., Romas, M., Medford, M., Leffert, N., \& Hatcher, S. L. (2006). Adult helping qualities preferred by adolescents. Adolescence, 41(161), 127-141.

McAra, L., \& McVie, S. (2010). Youth crime and justice: Key messages from the Edinburgh study of youth transitions and crime. Criminology \& Criminal Justice, 10(2), 179-209.

Muncie, J. (2015). Youth and crime. London: Sage.

Northern Ireland Social Care Council. (2015). Standards of conduct and practice for social workers. Belfast: NISCC.

O’Brien, M. (2011). Social justice: Alive and well (partly) in social work practice? International Social Work, 54(2), 174-190. 
Parton, N. (1998). Risk, advanced liberalism and child welfare: The need to rediscover uncertainty and ambiguity. The British Journal of Social Work, 28(1), 5-27.

Pinkney, S. (2011). Participation and emotions: Troubling encounters between children and social welfare professionals. Children and Society, 25(1), 37-46.

Pitts, J. (2013). Reluctant gangsters: The changing face of youth crime. Devon: Willan.

Seale, C., Gobo, G., Gubrium, J. F., \& Silverman, D. (Eds.). (2004). Qualitative research practice. London: Sage.

Skinner, D. (2010). Effective teaching and learning in practice. London: Continuum International Publishing Group.

Stanford, S. (2011). Constructing moral responses to risk: A framework for hopeful social work practice. The British Journal of Social Work, 41(8), 1514-1531.

Stein, M. (2015). Supportive pathways for young people leaving care, lessons from four decades of research. In J. Whittaker, J. Del Valle, \& L. Holmes (Eds.), Therapeutic residential care for children and youth, developing evidence-based international practice (pp. 189-202). London: JKP.

Stewart, D. W., \& Shamdasani, P. N. (2015). Group dynamics and focus group research. Focus Groups: Theory and Practice, Chap. 2, 17-38.

Taylor, C. (2016). Review of the youth justice system in England and Wales. UK: Ministry of Justice. 